\title{
The Role of Precursor States in Adsorption, Surface Reactions and Catalysis
}

\author{
Michael Bowker ${ }^{1,2}$
}

Published online: 28 March 2016

(c) The Author(s) 2016. This article is published with open access at Springerlink.com

\begin{abstract}
Among the many concepts which have been developed in surface science and catalysis to explain the nature of adsorption, the role of weakly-held states, socalled precursor states, is one of the most important. The kinetics of precursor-mediated adsorption is described, together with examples showing how significant such effects can be, not just in adsorption itself, but also in surface reactions on crystals and on model supported catalysts. These examples include $\mathrm{CO}$ adsorption on $\mathrm{Pd}$ single crystals and catalysts and implications for $\mathrm{CO}$ oxidation, and extreme examples of the precursor effect, where adsorbate molecules can appear to 'seek out' active sites which are in very low concentration on the surface. The decomposition and oxidation of formic acid is just such an example. Such reactivity patterns then also lead to concepts such as the collection zone' or 'diffusion circle' describing how much of an area of surface is 'swept' by incoming weakly-held molecules during their brief sojourn there.
\end{abstract}

Keywords Precursor states - Physisorbed states · Adsorption kinetics · Sticking probabilities · CO adsorption $\cdot \mathrm{CO}$ oxidation $\cdot$ Formic acid

Michael Bowker

bowkerm@cardiff.ac.uk

1 Cardiff Catalysis Institute, School of Chemistry, Cardiff University, Cardiff CF10 3AT, UK

2 UK Catalysis Hub, Research Complex at Harwell (RCaH), Rutherford Appleton Laboratory, Harwell, Oxon OX11 0FA, UK

\section{Introduction}

The purpose of this paper is to consider the role of relatively short-lived, intermediate states, often called 'precursor' states, in the kinetics of adsorption and surface reactions. It is the case that almost all, if not all, catalytic reactions carried out on the industrial scale rely on the chemisorption of the reactant on the surface, so that significant bond transformation can take place. This occurs via reactant bond weakening, and the transfer of atoms, either internally within the molecule or between molecules/atoms. The surface mediates this process by forming the adsorbed state and the kinetics of these transformations can often be rate-determining in catalysis. Hence it is important to consider the role of physisorbed species in these processes.

\section{Precursor States', 'Transients', 'Intermediates', Some Definitions}

It is clear that chemisorption can be preceded by physisorption and that this state, and the energetics of its adsorption, must play an important role in the adsorption process. Thus we can consider adsorption to occur as follows:

$\mathrm{A} \Leftrightarrow \operatorname{Pr}+\mathrm{s} \rightarrow \mathrm{I}_{\mathrm{a}} \rightarrow \mathrm{z}+\mathrm{y}$

where $A$ is the adsorbing molecule, $s$ is a surface site, $I_{a}$ is some intermediate species on the surface and $\mathrm{z}$ and $\mathrm{y}$ are, this case, gas phase break-down products of $\mathrm{A}$, and we use the symbol Pr to represent the physisorbed state, though we may more generally refer to it, as many others before have, as the 'precursor' state.

At this stage let us make a very simple definition of the 'precursor state', It is a species which has thermally 
accommodated to the surface temperature, but which has a short, but nevertheless significant, lifetime on the surface compared to the lifetime of the strongly adsorbed state Ia. The precursor can exist over both empty and filled sites on the surface. $I_{a}$ may either be the final adsorbed state, or may proceed to product formation. Many measurements in surface science do not proceed to products $\mathrm{z}$ and $\mathrm{y}$ in scheme 1 (although we will describe some that do below) and so $I_{a}$ is indeed often the final state of the adsorption measurement and $I_{a}$ is essentially stable and long-lived, that is, the experiment is carried out below it's decomposition/desorption temperature.

A distinction from 'transient' or even 'transition' states is that these can be chemisorbed species, occupying specific adsorption sites at the surface (though the 'transient' can also have some mobility on the surface [1]), whereas the precursor does not occupy chemisorption sites.

It was found very early in the era of adsorption measurements that the sticking probability (and hence adsorption rate) did not follow the sharp decrease with increasing coverage which might have been expected from the original Langmuir considerations. For example, in the work of Becker and Hartman [2] for a nitrogen adsorption on a $\mathrm{W}$ film, together with results from King et al. for planar W(100) [3] and a stepped surfaces, W(320) [4] the sticking probability stays high, for instance, at 0.4 monolayer coverage on the (100) surface the adsorption rate is far higher ( $\mathrm{S} /$ $\left.\mathrm{S}_{0}=0.7\right)$ than might be expected on the basis of the relatively few remaining clean pair sites on the surface (it should be 0.03 ). The more complex nature of adsorption had already been considered in 1933 by Taylor and Langmuir [5] who proposed the idea that diffusion in a weakly-held layer had a role in adsorption; this was needed in order to explain the high sticking probability of Cs on tungsten, even as coverage approached saturation. In two seminal papers in 1957 Kisliuk, working at Bell Labs presented an analytical approach to understanding such high adsorption rates [6, 7]. He quantified the importance of diffusion in the physisorbed (as he considered it to be) 'precursor' state and in two elegant papers, he outlined the mathematical application of such an idea, which is pictorially outlined in Fig. 1. Here it is considered that there are two types of precursor which have mobility in this weakly held state- 'extrinsic' (that over a filled site) and 'intrinsic' (that over an empty chemisorption site) [8]. The adsorption rate then depends upon the rate of adsorption from the intrinsic state and the rate of diffusion of the extrinsic state to empty sites where it can adsorb. Summing all these probabilities results in a simple modification to the Langmuir-type adsorption rate, as follows

$\mathrm{S}=\mathrm{S}_{0}\{1+(\operatorname{Kp} \theta /(1-\theta))\}^{-1}$

The resulting dependence of sticking upon coverage is given in Fig. 2, for a variety of values of Kp. Here it can be

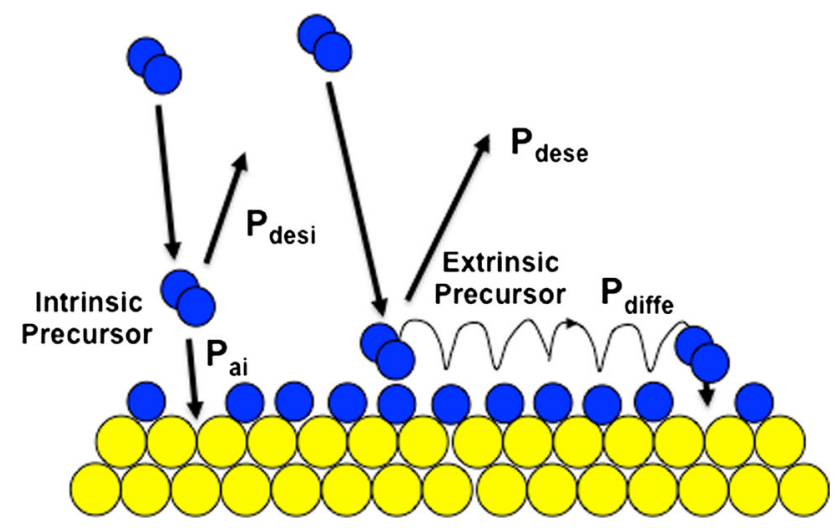

Fig. 1 Showing adsorption into the precursor state over filled (extrinsic) sites and empty (intrinsic) sites. The intrinsic state can adsorb $\left(\mathrm{P}_{\mathrm{ai}}\right)$, or desorb $\left(\mathrm{P}_{\text {desi }}\right)$, or diffuse to another site (not shown) from adsorption over an empty site at the surface. In contrast, the extrinsic precursor adsorbs on parts of the surface with filled chemisorption sites. It can then either desorb $\left(\mathrm{P}_{\text {dese }}\right)$ or diffuse to an adjacent site $\left(\mathrm{P}_{\text {diffe }}\right)$ before eventually adsorbing at an empty site

seen that the equation reduces to the simple Langmuir form when $\mathrm{Kp}=1$ (that is, no role of the precursor), whereas when $\mathrm{Kp}$ is very small there is a very large precursor effect and $\mathrm{S}$ stays high to very high coverage. The so-called precursor state parameter $\mathrm{Kp}$ is given by basic probabilities as follows

$\mathrm{Kp}=\mathrm{S}_{0} \mathrm{P}_{\mathrm{de}} / \mathrm{P}_{\mathrm{ai}}$

where the probabilities are defined as shown in Fig. 1.

We can express the number of 'hops', $\mathrm{N}_{\mathrm{h}}$, that a molecule makes on the surface from the ratio of the Frenkel

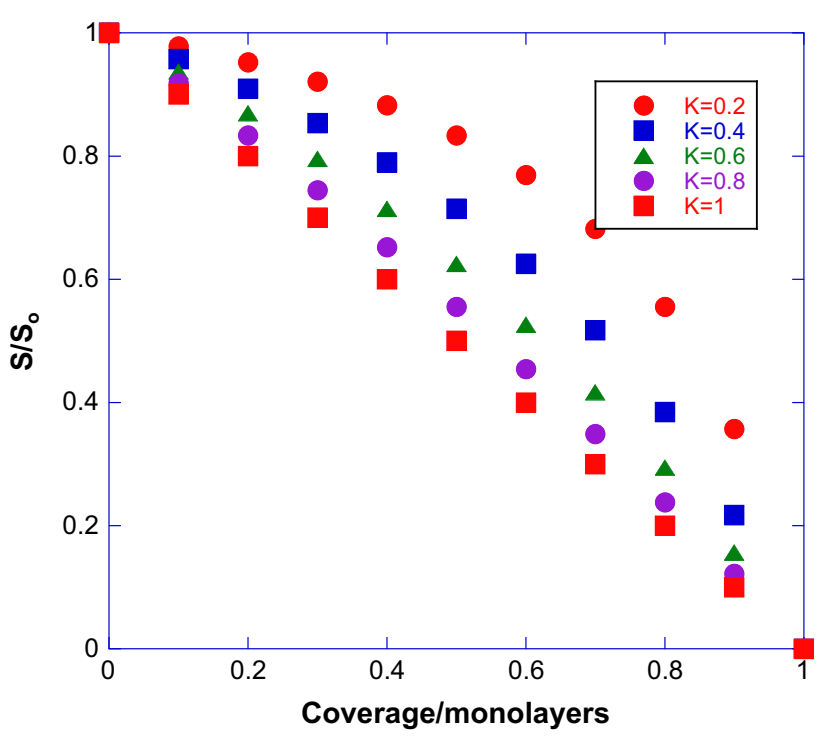

Fig. 2 The effect of the precursor parameter on the adsorption curve, $\mathrm{K}=1$ corresponds to no precursor effect and Langmuirian kinetics 
lifetime on the surface before desorption $\left(\tau_{\mathrm{des}}\right)$ to the lifetime for the hopping process $\left(\tau_{\text {diff }}\right)$ :

$$
\begin{aligned}
\mathrm{Nh} & =\tau_{\text {des }} / \tau_{\text {diff }}=\mathrm{k}_{\text {diff }} / \mathrm{k}_{\text {des }} \\
& =\left(\mathrm{A}_{\text {diff }} / \mathrm{A}_{\text {des }}\right) \exp \left\{\left(\mathrm{E}_{\text {des }}-\mathrm{E}_{\text {diff }}\right) / \mathrm{RT}\right\}
\end{aligned}
$$

Here we have also expressed the lifetimes in terms of inverse rate constants and their Arrhenius expansion. Further, if we assume $A_{\text {des }} \sim A_{\text {diff }}$, and that the diffusion activation energy is $1 / 3 \mathrm{rd}$ of the desorption energy, which is the approximate relationship from experimental determinations, then we can derive the data shown in Table 1 for a particular desorption energy which might be typical of physisorbed states (in this case $38 \mathrm{~kJ} \mathrm{~mol}^{-1}$ ). Though the lifetime of such a state at ambient temperature is very low, less than one microsecond, nonetheless it can diffuse over many sites, $\sim 30,000$ of them! We can re-interpret this in terms of a lateral extent of diffusion by using the concept of the 'diffusion circle' [9-12]. Here we simply consider the hops as distributed in a circle around the landing site on the surface (Fig. 3), and so we can describe the extent of the diffusion by the radius of this circle, that is,

$\mathrm{r} \sim\left(\mathrm{N}_{\mathrm{h}} / \pi\right)^{1 / 2}$

This is, of course, a somewhat simplistic approach, but it is useful to give an idea of the average diffusivity. In reality this diffusion is not a step function, as in Fig. 3, but is a distribution related to Fickian diffusion, that is,

$<\mathrm{x}^{2}>=\mathrm{Dt}$

And so the range of diffusion from the landing site is

Table 1 The dependence of physisorbed species lifetime and diffusivity upon surface temperature

\begin{tabular}{lllr}
\hline T/K & Nh & $\tau$ des/s & r/sites \\
\hline 200 & $4 \times 10^{6}$ & $8 \times 10^{-4}$ & 12000 \\
300 & $3 \times 10^{4}$ & $4 \times 10^{-7}$ & 90 \\
500 & 450 & $10^{-9}$ & 12 \\
\hline
\end{tabular}

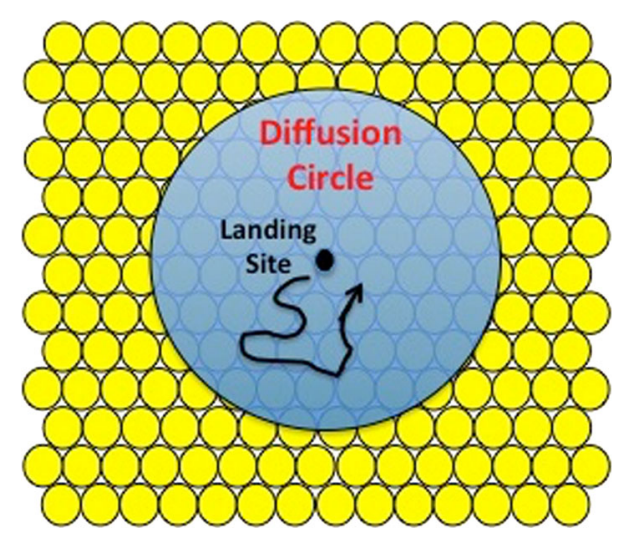

Fig. 3 The diffusion circle concept, indicating an area of the surface visited by the diffusing precursor state

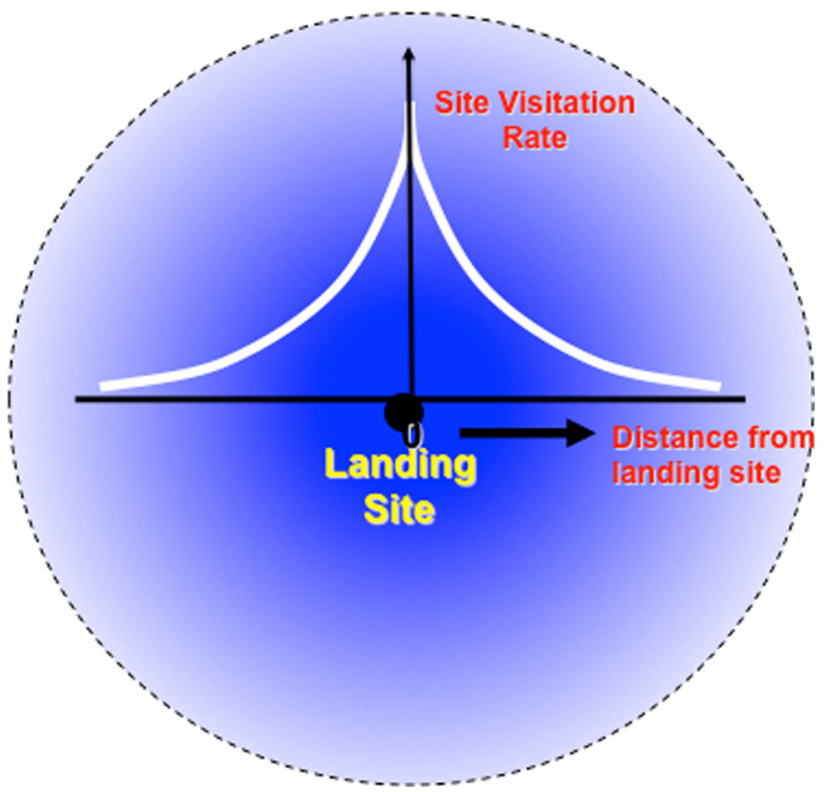

Fig. 4 The radial probability of diffusing different distances from the landing site

related to the square root of the time of residence at the surface.

$\mathrm{X}_{\mathrm{rms}}=(\mathrm{Dt})^{1 / 2}$

We can then plot the probability of diffusion in terms of the differential of this equation with respect to time, that is

$\mathrm{dx}_{\mathrm{rms}} / \mathrm{dt}=\mathrm{ct}^{-1 / 2}=\mathrm{d} / \mathrm{x}_{\mathrm{rms}}$

where $\mathrm{c}$ and $\mathrm{d}$ are constants. This gives the type of distribution shown in Fig. 4, with a big decrease in probability of finding the diffusing molecule away from the landing site. These diffusion concepts will be exemplified in the following sections.

\section{Practical Examples of Precursor States in Adsorption and Catalysis}

Various examples of the effect of precursor states follow, mainly from the work in our own laboratory. These show the important role of precursor states in adsorption itself, but which also show that they can play a critical role in surface reactions (that is, reactions in which the adsorbate transforms to another state and/or yields gas phase products).

\subsection{CO Adsorption on Transition Metals and the CO Oxidation Reaction}

Figure 5 shows a sticking probability curve for the adsorption of $\mathrm{CO}$ on $\mathrm{Pd}(110)$ [13]. There is no doubt that CO adsorbs molecularly, and it desorbs again in TPD with a peak at $\sim 450 \mathrm{~K}$. However, it is clear that the behaviour 


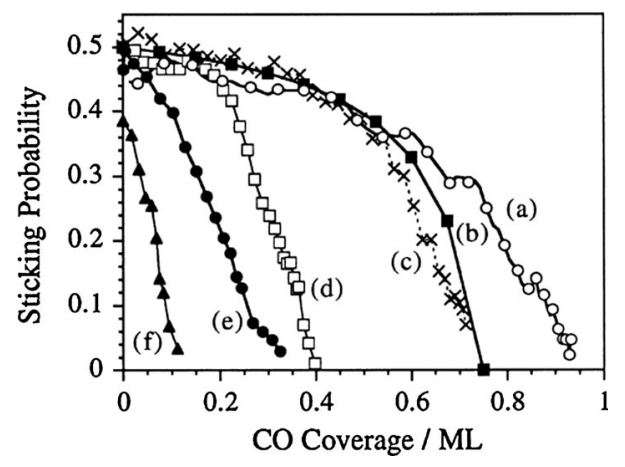

Fig. 5 The sticking of $\mathrm{CO}$ on $\mathrm{Pd}(110)$ as a function of coverage for a variety of surface temperatures: (a) $210 \mathrm{~K},(c) 327 \mathrm{~K}$, (d) $377 \mathrm{~K}$, (e) $423 \mathrm{~K},(f) 470 \mathrm{~K}$, while curve $(b)$ is the fit to the $327 \mathrm{~K}$ data using Eq. 2 with a precursor state parameter of 0.13

is non-Langmuirian and that the sticking stays high as the coverage increases, only decreasing significantly at high coverages. Applying Eq. 2 above gives a value for $\mathrm{K}$ of 0.13 , indicating a significant effect and hence the large curvature of the sticking plot.

As mentioned in Sect. 2 above, the sticking probability measured may indeed be a net sticking probability if the desorption rate from the adsorbed state is significant during the timescale of the measurement. Thus, although the apparent sticking probability becomes close to zero in Fig. $5 \mathrm{f}$ at a temperature of $470 \mathrm{~K}$ and a coverage of $\sim 0.1$, this is due to a high rate of desorption from the chemisorbed state at that temperature.

Curve shapes of the type shown in Fig. 5 seem to be very general for $\mathrm{CO}$ adsorption, at least for the transition elements. Thus similar curve shapes are seen for adsorption on $\mathrm{Rh}(110)$ [14], $\mathrm{Cu}(110)$ [15, 16], $\operatorname{Ir}(110)$ [17] and $\mathrm{W}(320)$ [18] for instance.

Because of its importance in adsorption the precursor state can also play a major role in reactions such as $\mathrm{CO}$ oxidation. It has been shown that the precursor state for $\mathrm{CO}$ has a strong influence on the nature of the $\mathrm{CO}$ oxidation reaction on metal single crystals. Thus for $\mathrm{Rh}(110) \mathrm{CO}$ adsorption itself is precursor influenced, but so also is the $\mathrm{CO}$ oxidation reaction and including the precursor state in the kinetic model was essential to modelling $\mathrm{CO}$ oxidation over a wide range of reaction temperature [19].

\subsection{Mobile Precursors Result in Increased Surface Reaction Rates: Oxygenates on $\mathrm{Cu}(110)$}

The examples given above were for relatively simple adsorption processes, but we will now consider situations in which the precursor state interacts with another species with which it reacts-such as acid-base reactions. First of all let us consider the reaction between pre-adsorbed oxygen atoms (the base) and gas phase formic acid. The

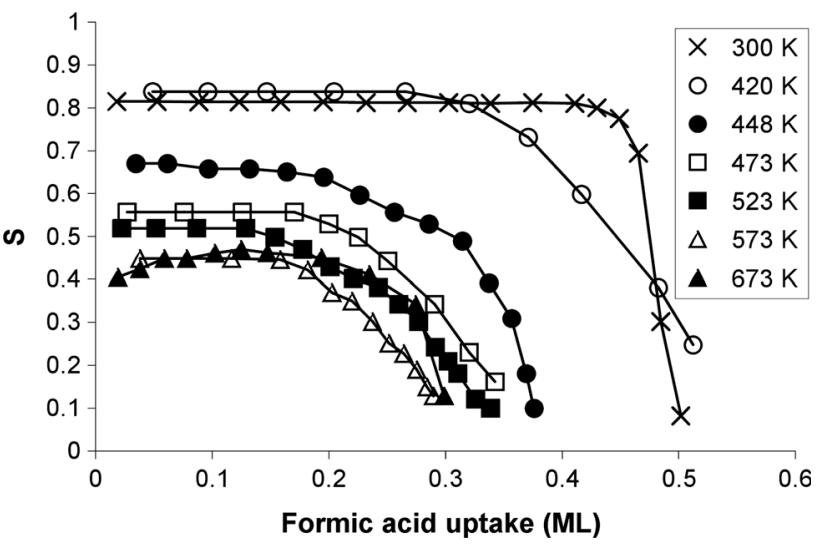

Fig. 6 Formic acid sticking probability dependence of uptake on $\mathrm{Cu}(110)$, for 0.25 monolayers of preadsorbed atomic oxygen, at a variety of crystal temperatures [20,23]. Note the independence of $S$ upon uptake at $300 \mathrm{~K}$ up to $\sim 90 \%$ of the maximum uptake

sticking probability of formic acid is low, at $\sim 0.1[20,21]$, but upon pre-adsorption of oxygen atoms the reaction probability is very high at 0.82 (see Fig. 6) [20, 22]. This is because it is more difficult for the formic acid to dissociate on the clean surface sites, but the oxygen atoms are able to strip off the acidic hydrogen to produce adsorbed formate in the following way, much more efficiently, via a physisorbed formic acid molecule:

$\mathrm{HCOOH} \rightarrow \mathrm{HCOOHp}$

$\mathrm{HCOOHp}+\mathrm{Oa} \rightarrow \mathrm{HCOOa}+\mathrm{OHa}$

As Fig. 6 shows the initial sticking probability is very high, and remains constant during most of the reaction, until almost all the oxygen is used up. This is due to the high mobility of formic acid in the precursor state which enables it to 'seek out' remaining oxygen atoms, even as their coverage becomes very low on the surface. This is even more obvious if only a very small amount of oxygen is dosed onto the surface. Even with only 0.03 monolayers of pre-adsorbed oxygen, $S_{0}$ is still 0.82 . Once again, this is due to the precursor molecules diffusing around the surface and finding the oxygen atoms with high efficiency.

We were able to examine this effect in even more detail for propan-2-ol, where we could measure the adsorption at pre-coverages of oxygen atoms as low as 0.008 monolayers [9]. The net sticking probability is close to zero on the clean copper surface, but is increased to 0.75 with this very low pre-coverage of oxygen atoms, and demonstrates the extreme mobility of the alcohol molecules in the weakly held layer.

This reaction of formic was modelled in some detail for the case where a quarter of a monolayer of oxygen was preadsorbed; it was essential for the modelling to include the precursor state influence on the adsorption, since this was required to fit the flat plateau of the sticking versus time 
shown in Fig. 6 [23]. This is a difficult system to model over a range of adsorption temperatures because gas phase reaction products are also evolved during the reaction $\left(\mathrm{CO}_{2}, \mathrm{H}_{2}\right.$ and $\left.\mathrm{H}_{2} \mathrm{O}\right)$, and also the stoichiometry of the reaction varies with temperature. Further, the active sites are located at the oxygen atomic sites, so that the reaction rate modelling has to include oxygen coverage, in the following way:

$$
\mathrm{R}_{1}=\mathrm{A}_{1} \times \exp \left(-\mathrm{E}_{1} / \mathrm{RT}\right) \times\left(1+\left(\mathrm{K} \times\left[1-\theta_{0}\right] / \theta_{0}\right)^{-1}\right.
$$

A very good fit to the data is obtained by this approach (Fig. 7); the stoichiometry change with temperature, and the change in product ratios from the formate reaction with oxygen could be fitted by taking into account the formate stability and the importance of precursor state adsorption which has been obtained from surface science investigations from several groups [21-26]. The product evolution depends upon temperature in the following way. At intermediate temperatures where the formate can decompose (up to $\sim 400 \mathrm{~K}$ ) the reaction is:

$2 \mathrm{HCOOH}+\mathrm{O}_{\mathrm{a}} \rightarrow \mathrm{CO}_{2}+\mathrm{H}_{2}+\mathrm{H}_{2} \mathrm{O}$

Whereas at higher temperatures the reaction shifts to,

$$
\mathrm{HCOOH}+\mathrm{O}_{a} \rightarrow \mathrm{CO}_{2}+\mathrm{H}_{2} \mathrm{O}
$$

the reaction proceeds exclusively this manner at $680 \mathrm{~K}$. The reason for this is that at the lower temperatures the formate decomposes only slowly at that temperature. Thus a second formic acid molecule can react with the $\mathrm{OH}$ formed from the primary reaction, before a hydrogen atom is liberated from the formate by decomposition. However, at the higher temperatures, in contrast, the formate

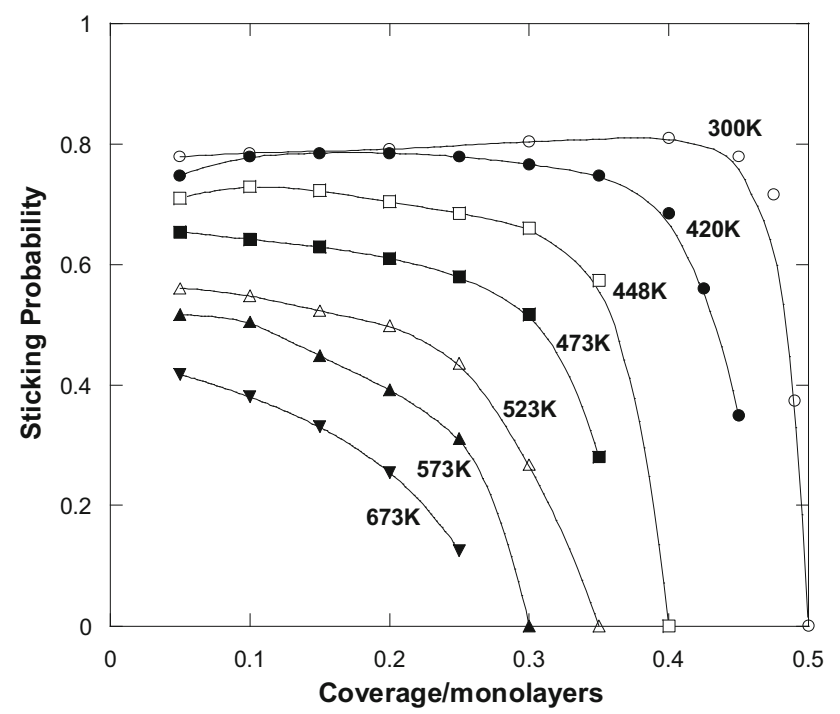

Fig. 7 Theoretical modelling of formic acid uptake curves at a variety of adsorption temperatures upon a $\mathrm{Cu}(110)$ surface with 0.25 monolayers of oxygen preadsorbed [23]

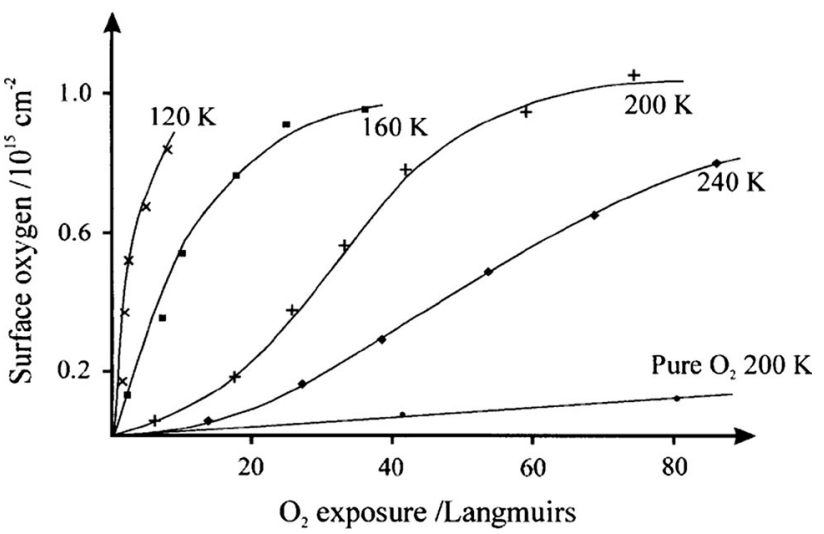

Fig. 8 XPS measurements of the uptake of oxygen onto $\mathrm{Zn}(0001)$ from the work of Roberts et al. [27]. It shows the large sticking increase when ammonia is incorporated into a gas feed compared with the pure $\mathrm{O}_{2}$ case

decomposition is fast and so $\mathrm{H}$ atoms from it react with $\mathrm{OH}$ before another formic acid molecule does [20, 23].

Roberts et al. [1, 27-29] have reported surface reactions which are of an inverse type, that is, oxygen adsorption itself is enhanced via the precursor state. In these experiments oxygen was not pre-adsorbed, but precursors are pivotal for high reaction rates to be seen. In particular they investigated the reaction between oxygen and ammonia on $\mathrm{Zn}(0001)$. Oxygen adsorption on the clean surface was found to be very slow (the estimated sticking probability was $\sim 10^{-3}$ ), yet it was enhanced to a very high value when both oxygen and ammonia were co-dosed, Fig. 8 [1, 27]. It was proposed that this was due to a mobile, precursor molecular oxygen " $\mathrm{O}_{2}^{\delta-}$ " species, interacting with ammonia in the weakly-held state. This enabled facile $\mathrm{O}_{2}$ dissociation, and hence a higher net sticking probability for oxygen into a long-lived state.

\subsection{Precursor States Can "Seek and Find" the Active Site on Model Catalysts and High Area Catalysts}

Some time ago Boudart et al. reported some unusual findings for the adsorption of hydrogen on glass and also for the oxidation of carbon monoxide on Pt catalysts supported on sapphire [30, 31]. They discovered that the rate of CO oxidation was considerably higher than expected on the basis of the measured areal coverage of Pt nanoparticles on the catalyst surface. Boudart's explained this in terms of reverse spillover of $\mathrm{CO}$ to the metal from the support, proposing the 'collection zone' concept, which is discussed below.

In more recent times surface science has advanced in the complexity of materials which can be fabricated and analysed in situ. This includes the production of model materials, for instance, nanoparticles have been deposited 
on well-defined support surfaces, either in the form of single crystal oxides $[32,33]$ or as thin film oxides on top of metals $[34,35]$. As a result some surface studies have returned to study the collection zone idea, though it has also been expressed in different terms as the 'diffusion circle' described above, as a shorthand way of describing the extent of diffusion of a precursor state on the surface [36]. Matolin et al. performed a series of elegant experiments by and found a significant enhancement of the sticking of $\mathrm{CO}$ on model supported Pd catalysts, using a number of different types of support material [37-40]. They incorporated this idea of CO mobility into a formulation for the sticking. This essentially consists of two parts-that arising from those molecules adsorbed weakly in the capture zone and that due to a fraction directly adsorbing on the Pd particles. For the situation in which metal nanoparticles are well-separated and capture zones do not overlap:

$\mathrm{S}_{\mathrm{m}}=\left\{\mathrm{S}_{\mathrm{su}} \mathrm{Z}_{\mathrm{d}}\left(2 \mathrm{r}+\mathrm{Z}_{\mathrm{d}}\right)+\mathrm{S}_{\mathrm{Pd} .} \mathrm{r}^{2}\right\} \pi \mathrm{n}$

where $S_{m}$ is the measured sticking probability, $S_{\mathrm{su}}$ is that for $\mathrm{CO}$ on the support, $\mathrm{S}_{\mathrm{Pd}}$ that on the metal particles of radius $r, n$ is the particle density and $X_{d}$ is the extent distance of the capture zone from the Pd particle. Even though this has many assumptions incorporated into it (homogeneous particle size distribution, a finite limit to the capture zone, etc.), they nonetheless could model the process with good success.

Henry et al. [32, 41, 42] also developed these kinds of ideas and have experimented with molecular beams, going beyond adsorption to catalytic reaction. They stress the importance of accounting for the extent of the capture zone effect when interpreting the effects on catalytic reactivity of particle size, an example being the $\mathrm{CO} / \mathrm{NO}$ reaction on $\mathrm{Pd} / \mathrm{MgO}$ model catalysts [42]. The capture zone can result in higher reaction rates than might be otherwise expected by the Pd coverage on the support $\mathrm{MgO}$, but the magnitude depends on the number density of the particles on the surface. Several theoretical descriptions have evolved [4345], and Zhdanov and Kasemo [45] have applied MonteCarlo modeling to the effect of the diffusion around nanoparticles on the bi-stability profiles (rate versus pressure variation) of bimolecular surface reactions. There can be significant shifts of the maximum to lower reactant pressure due to such effects

We have measured the adsorption of carbon monoxide on Pd nanoparticles (of $\sim 4 \mathrm{~nm}$ diameter) [36] and have found a gain of the sticking probability of $\mathrm{CO}$ of a factor of $\sim 5$ over what would be anticipated from the areal coverage of the surface by Pd nanoparticles. This arises from the influence of the precursor state, and this effect is shown in Fig. 9, and schematically illustrated in Fig. 10. The adsorption is of two main types as described above-direct

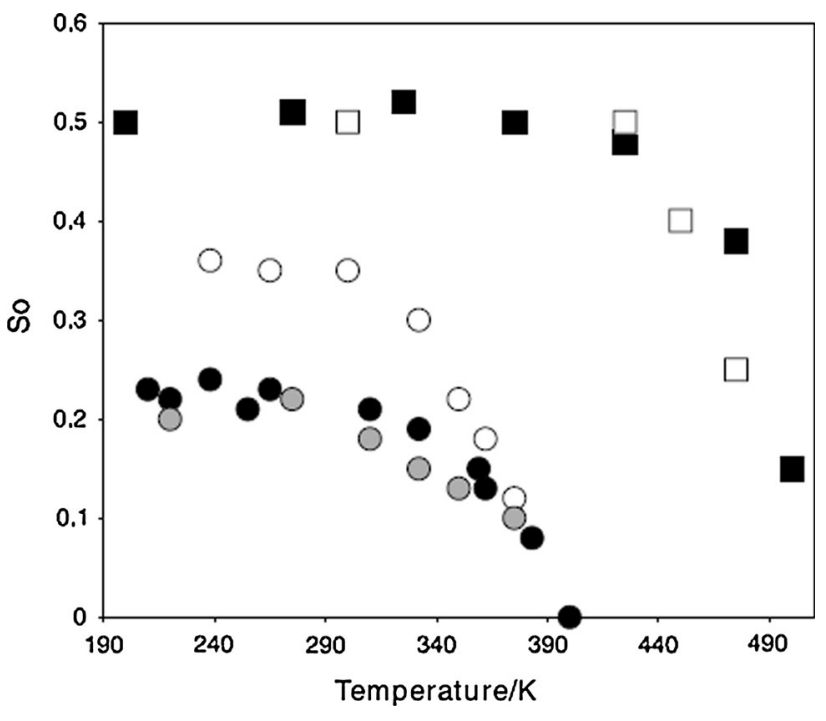

Fig. 9 The dependence of initial (low coverage) sticking probability upon temperature for $\mathrm{Pd}(110)$ (filled squares) $\mathrm{Pd}(111)$ (open squares) and for three different loadings of the $\mathrm{TiO}_{2}(110)$ surface with $\mathrm{Pd}$ (open circles, $35 \%$; filled circles, $12 \%$; grey circles, $8 \%$ ) [36]

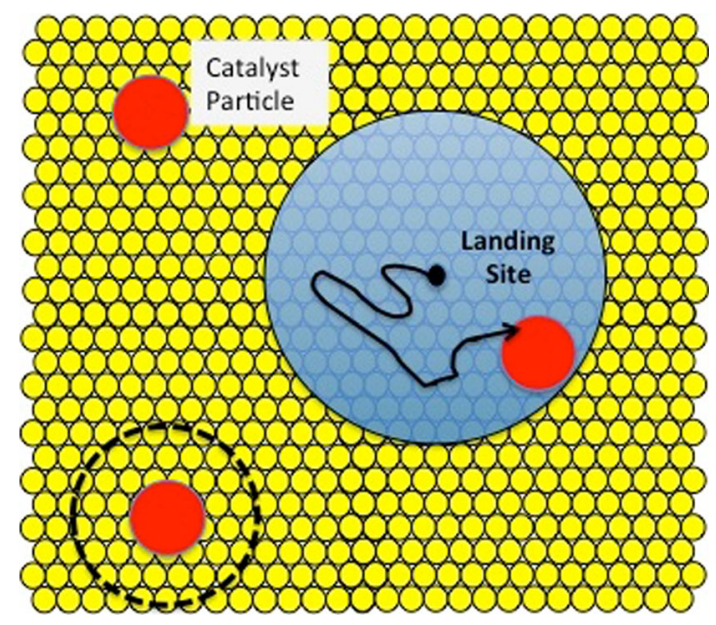

Fig. 10 Illustrating a surface with a dilute distribution of metallic nanoparticles present (red circles), and a molecule landing remotely from them. Because the diffusion circle is large enough the molecule nevertheless has a high probability of finding a particle within its zone of diffusion where it then becomes trapped into a long-lived, chemisorbed state. Also shown is the 'collection zone' concept of Boudart (dashed circle) [30, 31] (Color figure online)

adsorption on the nanoparticles, plus that from a diffusing flux of $\mathrm{CO}$ via the precursor state on the support. The adsorption of $\mathrm{CO}$ on oxidic surfaces is generally weak, usually $\sim 20-50 \mathrm{~kJ} \mathrm{~mol}^{-1}$, and so the lifetime at $300 \mathrm{~K}$ is very short. The best fit to the data was obtained with $38 \mathrm{~kJ} \mathrm{~mol}^{-1}$ binding energy; the lifetime is $\sim 10^{-7} \mathrm{~s}$ at $300 \mathrm{~K}$, and so the radius of the 'diffusion circle' on the support would be about $2 \mathrm{~nm}$. Thus the particle (of approximate cross-sectional area $12 \mathrm{~nm}^{2}$ ) would capture $\mathrm{CO}$ molecules from an area on the support of about four 


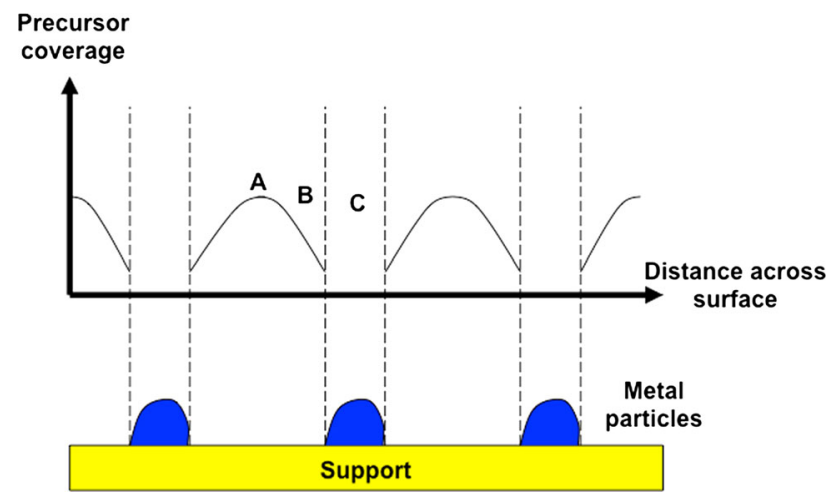

Fig. 11 Schematic diagram of the distribution of precursor state coverage as a function of position on the surface (upper panel) of an array of supported metal nanoparticles supported (lower panel). The metal particle is in region $C$, while $A$ is the point of maximised precursor coverage at the bisect of adjacent particles. $B$ is a region of depleted precursor coverage, due to loss of molecules to the metal by non-equilibrium diffusion onto them and loss from the precursor layer

times it's own area, and so there is the significant enhancement of the CO sticking seen in these kinds of measurements. In Fig. 10 the Boudart proposal of the collection zone is shown too, which reflects the higher cross-section for adsorption on to the particles, and the diffusion circle is just another way of expressing this idea.

Besides the considerations above it must be remembered that there will not be an isotropic distribution of precursor molecule concentration on a surface with active nanoparticles around as pointed out by Henry et al. [41]. As shown in Fig. 11 there will be loss of the $\mathrm{CO}$ near the nanoparticles since, on the support, the coverage will be determined by the equilibrium with the gas phase, as follows

$\mathrm{CO}_{\mathrm{g}} \rightarrow \mathrm{CO}_{\mathrm{p}}$
$\mathrm{CO}_{\mathrm{p}} \rightarrow \mathrm{CO}_{\mathrm{g}}$

whereas when a particle is nearby there is an additional kinetic process draining the precursor $\mathrm{CO}$ coverage as follows:

$\mathrm{CO}_{\mathrm{p}} \rightarrow \mathrm{CO}_{\mathrm{a}, \mathrm{Pd}}$

This results in the depletion of precursor state illustrated schematically in Fig. 11. What this shows is a concentration reduction around the particles from that far from the particle. Of course, the adsorption situation is not at equilibrium and is dominated by the kinetics of the chemisorption onto the metal nanoparticles, and so the situation illustrated in Fig. 11 would change as the metal becomes saturated with adsorbate and the precursor concentration around the particle would then become isotropic. If we consider a reacting system, $\mathrm{CO}$ oxidation for instance, there will be a continuous loss of precursor from the support in the way shown in Fig. 11.

\section{The Significance of Precursor States in Industrial Heterogeneous Catalysis}

Clearly, then, precursor states have a major role to play in adsorption, on both single crystals and on nanoparticulate catalysts, and can strongly affect reaction kinetics, as in the example of formic acid oxidation above. However, will they be of any significance in industrial scale catalysis? The answer is yes, but it depends very much on which types of reaction are involved. If the reaction is carried out at relatively low temperature, using large molecules, such as hydrocarbon dehydrogenation reactions, which often take place $\sim 400 \mathrm{~K}$, then the precursor, physisorbed form of the hydrocarbon will be important and will affect the kinetics. On the other hand it will be much less significant for high temperature reactions using small molecules, for example, methane steam reforming on Ni catalysts, taking place at $\sim 1000 \mathrm{~K}$, and for which the lifetime of the low molecular weight precursor will be very short. In many cases in catalysis, the 'active site' may have very small coverage on the surface. For instance, in naphtha reforming on $\mathrm{Pt} / \mathrm{SiO}_{2}$ catalysts the $\mathrm{Pt}$ loading is only $\sim 0.3 \%$; in oxide catalysts sometimes the active site is a defect centre which may be sparsely distributed on the surface [46]. As described above 'light-off' in automobile catalysts is affected by the diffusivity of $\mathrm{CO}$ across the supported metal surface. From all these considerations it can be concluded that the properties of such weakly-held states affect the kinetics in some major industrial processes too.

Open Access This article is distributed under the terms of the Creative Commons Attribution 4.0 International License (http://crea tivecommons.org/licenses/by/4.0/), which permits unrestricted use, distribution, and reproduction in any medium, provided you give appropriate credit to the original author(s) and the source, provide a link to the Creative Commons license, and indicate if changes were made.

\section{References}

1. Carley AF, Davies PR, Roberts MW (2002) Catal Lett 80:25

2. Becker JA, Hartmann CD (1953) J Phys Chem 57:153

3. King DA, Wells MG (1974) Proc R Soc Lond A 339:245

4. Singh-Boparai SP, Bowker M, King DA (1975) Surf Sci 53:55

5. Taylor JB, Langmuir I (1933) Phys Rev 44:423

6. Kisliuk P (1957) J Phys Chem Solids 3:95

7. Kisliuk P (1958) J Phys Chem Solids 5:78

8. Alnot P, Cassuto A, King DA (1989) Surf Sci 215:29

9. Bowker M, Pudney P (1990) Catal Lett 6:13

10. Bowker M (1994) Surf Rev Lett 1:549

11. Bowker M, Bowker L, Bennett R et al (2000) J Mol Catal A 163:221

12. Bowker M (2010) J Phys 22:263002

13. Jones IZ, Bennett RA, Bowker M (1999) Surf Sci 439:235

14. Bowker M, Guo Q, Joyner R (1991) Surf Sci 253:33

15. Kunat M, Boas C, Becker T et al (2001) Surf Sci 474:114

16. Burghaus U (2003) Surf Rev Lett 10:7 
17. Burghaus U, Ding J, Weinberg WH (1997) Surf Sci 384:L869

18. Bowker M, King DA (1980) J Chem Soc Faraday I 76:758

19. Bowker M, Guo Q, Joyner RW (1993) Surf Sci 280:50

20. Bowker M, Rowbotham E, Leibsle F, Haq S (1996) Surf Sci 349:97

21. Bowker M, Haq S, Holroyd R et al (1996) J Chem Soc Faraday Trans 92:4683

22. Bowker M, Bennett RA, Poulston S, Stone P (1998) Catal Lett $56: 77$

23. Youngs TGA, Haq S, Bowker M (2008) Surf Sci 602:1775

24. Ying D, Madix RJ (1980) J Catal 61:48

25. Wachs I, Madix RJ (1979) Surf Sci 84:375

26. Hayden B, Prince K, Woodruff DP, Bradshaw A (1983) Surf Sci 133:589

27. Carley AF, Roberts MW, Yan S (1990) J Chem Soc Faraday Trans 86:2701

28. Carley A F, Davies P R, Roberts, et al (1998) J. Chem. Soc. Chem. Comm. 35

29. Carley AF, Davies PR, Roberts MW (2005) Phil Trans R Soc A $362: 829$
30. Tau K, Boudart M (1961) Actes du Deuxieme Congres International de Catalyse, vol 1. Technip, Paris, p 593

31. Rumpf F, Poppa H, Boudart M (1988) Langmuir 4:722

32. Henry CR (1998) Surf Sci Rep 31:231

33. Bowker M (2007) Chem Soc Rev 36:1656

34. Nilius N (2009) Surf Sci Rep 64:595

35. Freund H-J (2005) Catal Today 100:3

36. Bowker M, Stone P, Bennett RA, Perkins N (2002) Surf Sci 497:155

37. Matolin V, Gillet E (1986) Surf Sci 166:L115

38. Matolin V, Gillet E, Kruse N (1987) Surf Sci 186:L541

39. Jungwirthova I, Stara I, Matolin V (1997) Surf Sci 377-9:644

40. Matolin V, Stara I (1998) Surf Sci 398:117

41. Henry CR, Chapon C, Duriez C (1991) J Chem Phys 93:700

42. Piccolo L, Henry CR (2000) Appl Surf Sci 162-3:670

43. Aris R (1971) J Catal 22:282

44. Kuan D-J, Davis HT, Aris R (1983) Chem Eng Sci 38:719

45. Zhdanov VP, Kasemo B (1997) J Catal 170:377

46. Bowker M, House M, Alshehri A et al (2015) Catal Struct React 1:95-100 